\title{
Gender Self-Presentations in the 2020 U.S. Elections
}

\author{
Pamela Aronson ${ }^{1 *}$, Leah Oldham ${ }^{1}$, Emily Lucas ${ }^{1}$ \\ ${ }^{1}$ University of Michigan-Dearborn, USA
}

*Corresponding Author: aronsonp@umich.edu

Citation: Aronson, P., Oldham, L. and Lucas, E. (2020). Gender Self-Presentations in the 2020 U.S. Elections, Journal of Cultural Analysis and Social Change, 5(1), 01. https://doi.org/10.20897/jcasc/8379

Published Online: July 2, 2020

\begin{abstract}
Ironically, the 2016 election of Donald Trump catalyzed progressive social change in the U.S.. A record number of women and people of color ran for the 2020 presidential nomination of the Democratic party. This election also saw the first openly gay candidate for president. Drawing on qualitative website and Twitter bio data, this article examines the gender self-presentations of twelve Democratic party primary presidential candidates--the eight men and four women who were in the primary debates in October 2019. We develop a new typology of gender self-presentation by classifying different approaches on a spectrum, ranging from gender traditional on one side to feminist on the other (with gender neutral and gender nontraditional in between). We find that most candidates simultaneously blend different types of gender self-presentations in their campaigns. For both men and women in the 2020 election, traditional selfpresentations are the least common and gender neutral self-presentations are the most common. For women, nontraditional self-presentations de-emphasize the traditional role of motherhood, use stereotypically masculine language, or emphasize nontraditional gender career experiences. In contrast, for the men, the nontraditional self-presentations were more narrow and stayed solely in the domain of fatherhood. Finally, feminist self-presentations emphasize women's social and political interests as women, either through the use of pronouns in their Twitter bios or through a discussion of feminist policy issues in websites. While both male and female candidates emphasize feminist issues, the men often do so by drawing on traditionally masculine language or highlight gender stereotypes as male protectors over vulnerable women. Together, these findings suggest that women's identities as candidates draw on a wider, more multifaceted, range of gender self-presentations. This nuanced typology can be applied to future research on gender and elections.
\end{abstract}

Keywords: gender, politics, elections, self-presentation, women candidates

\section{INTRODUCTION}

In the shadow of the 2016 election of Donald Trump, the 2018 midterm elections were distinct in the ways that women candidates represented gender in their campaigns. Campaign advertisements featured candidates pregnant or breastfeeding, highlighted their experiences with sexual assault or harassment, emphasized their military credentials, and showed images of them protesting Trump's inauguration (Aronson, Oldham, and Lucas, Under Review; Axios, 2018). The U.S. is in the midst of a gender revolution that is transforming women's power and identities (Aronson and Fleming, Under Review). Paradoxically, the defeat of Hillary Clinton by Donald Trump in the 2016 presidential election sparked dramatic social change in women's power. We have witnessed an explosion in women's movement activism, the rise of the \#MeToo movement, and a dramatic increase in the number of women running for office (Aronson and Fleming, Under Review). The 2020 election has witnessed a record number of women and people of color vying for the presidential nomination of the Democratic party, yet 
little scholarly work has been conducted about how the candidates are constructing their gender self-presentations. In the 2018 election, Democratic women, especially those from diverse racial and ethnic backgrounds, were elected in record numbers (Conroy, 2018).

Research has not yet systematically examined gender self-presentations of the 2020 Democratic party primary presidential candidates. Through a qualitative analysis, this article examines the ways in which these candidates present their gender identities on social media and websites. In doing so, we develop a new theoretical framework for understanding the spectrum of gender self-presentations utilized by both male and female candidates. We argue that this spectrum includes gender traditional, neutral, nontraditional, and feminist self-presentations. Our development of a new way of understanding the gender self-presentations of political candidates is important for several reasons. We are entering a new era of women in U.S. politics, with women and people of color running in unprecedented numbers and stepping outside of traditional gender stereotypes in their campaigns (See also Aronson, Oldham, and Lucas, Under Review). Previous research has only considered this issue in narrow gender dichotomous terms; it has not yet developed a complex understanding of candidates' gender self-presentations. In addition, the gendered content of self-presentations on social media and websites are undertheorized. In this paper, we develop a spectrum of self-presentations that can be applied to campaigns at any level or candidates of any gender. In a political context in which gender matters significantly, our new theoretical framework can help advance future research by encouraging more nuanced understandings of how politics is gendered.

\section{LITERATURE REVIEW}

\section{Gender and Elections}

While the public is generally supportive of women running for the highest political office in the U.S., not everyone supports this notion. A Gallup poll in 2011 asked, "Do you think the voters of this country are ready to elect a woman president, or don't you think so?" and only 78 agreed (Roper Center for Public Opinion Research 2017). Streb et al. (2008) asked about views toward a female president alongside other political issues (including "gasoline prices ... going up" and "large corporations polluting the environment") and found that slightly more than a quarter of both men and women were "angry or upset" about the possibility of a female president.

Women candidates at all levels face a no-win situation: many voters view them negatively if they violate gender stereotypes or if they are portrayed as too nurturing and sensitive (Bauer, 2015; Dittmar, 2015; Dwyer et al., 2009). As a result of the masculinity assumed in politics, women candidates and their strategists carefully weigh whether to draw on, minimize, or challenge gender stereotypes in their campaigns (Dittmar, 2015). In fact, they often aim to strike a "balance" between "feminine and masculine traits and issues" when it comes to both self-presentation and policy stances (Dittmar, 2015: 81). Previous studies find that women candidates running for executive offices typically adopt a "masculine" campaign style that emphasizes "toughness" and experience in male domains like defense, while minimizing attention to women's issues (Carroll, 2009; Dittmar, 2015). At the same time, in order to conform to norms surrounding femininity, women candidates pay close attention to their tone (i.e. "to be tough but not mean") and appearance (i.e. dress professionally to "neutralize gender"; Dittmar (2015: 89, 105). They may even have an advantage when they conform to gender norms that emphasize "feminine" traits such as honesty and authenticity, or highlight their "outsider" status (Dittmar, 2015). Some studies suggest that women candidates appeal to women voters when they emphasize stereotypical women's issues, such as education and child care (Herrnson et al., 2003). In fact, women candidates' websites are more likely to be "congruent" than "incongruent" with gender stereotypes (Schneider, 2013).

Prior studies typically emphasize a gender dichotomy, where women candidates either draw on or reject gender stereotypes. This dichotomous way of understanding gender in electoral politics is simplistic and fails to capture the full range of possible self-presentations. "Feminine stereotypes" emphasize women's traits as "warm, nurturing, and sensitive" or "communal" (Bauer, 2015: 691). In contrast, "masculine" traits are "aggressive," "agentic" (Bauer 2015) or focus on "leadership" (Schneider, 2013: 265). Although Dittmar's (2015) research goes the furthest toward trying to understand the complexity of self-presentation, this body of research as a whole does not examine the complexity of the ways that women candidates present themselves. Yet as West and Zimmerman (1987: 125) theorized in their classic essay, "doing gender" can be complex, and involves a "routine accomplishment embedded in everyday interaction." Like in person, gender is "performed" and represents an "accomplishment" (West and Zimmerman, 1987) in an online self-presentation; it is more complicated than a simple dichotomous expression of male or female stereotypes. Understanding how candidates "do gender" in complicated ways is important when examining their responses to the unique social rules that predominate in the political sphere. That is, politics involves enacting specific self-presentation norms. Although some self-presentations are expected of candidates regardless of gender, we examine how "doing gender" and "doing politics" intersects in complex ways. 
In particular, men who run against women typically alter their tactics (Dittmar, 2015). As Dittmar (2015: 130) put it, "mixed-gender contests force men to confront gender dynamics in ways they would not with male opponents." Men typically exercise care when critiquing a female opponent, so that they do not appear overly aggressive (Dittmar, 2015). They also may adjust their campaigns, including policy-based appeals and imagery, in order to appeal to women voters (Dittmar, 2015). While male candidates benefit from images of their families because it "softens" their self-presentation, women candidates use images of their families to "evoke empathy and provide alternative credentials for political leadership" (Dittmar, 2015: 111). In fact, Fridkin and Kenney (2015) found that 96 percent of male candidates mentioned family on their Senatorial webpages, while only 77 percent of female candidates did so.

Previous research focuses on stereotypical self-presentations or those that run against stereotypes (e.g. Dittmar, 2015; Herrnson et al., 2003; Lawrence et al., 2016; McGregor et al., 2017; Meeks, 2017), and examined campaigns prior to the contemporary period. Self-presentations in politics are in the midst of transformation, as we have entered a new era of women in politics (Aronson and Fleming, Under Review). Thus, the full range of gender selfpresentations in campaigns remains untheorized. The present paper pushes this analysis forward by introducing a new spectrum to understand candidates' self-presentation on social media and websites. Given the unprecedented dynamics of recent U.S. elections and the large number of women candidates running for the Democratic party nomination for president in 2020, our approach fills a much needed gap in the scholarship. It is important that researchers develop a more complex understanding of gender self-presentations in the current political context, as we are witnessing a new era of women in U.S. politics.

\section{Gender and Social Media}

Candidates have limited control over how gender is covered by the media (Meeks, 2017). In a recent study, Wagner (2019) found that the more powerful position a female candidate is seeking, the more likely she will be covered unfairly. Trimble et. al (2013) found that journalists and pundits emphasize women candidates' personal lives and bodies more often than those of male candidates. Of course, candidates also communicate directly with voters during debates and on the campaign trail, yet these formats are often mediated by media coverage. For example, as a candidate for the 2020 U.S. Democratic nomination for President, Elizabeth Warren's presence was often "erased" by the media (Ellefson, 2020). Social media and candidate websites, however, have created a shift to candidate self-presentation; women candidates can communicate directly with voters without the gender bias of the media (Fountaine, 2017; McDonnel, 2020; McGregor, 2018; Meeks, 2017; Schneider, 2013). Women candidates can utilize social media to overcome the obstacles they often face to visibility (Fountaine, 2017). Twitter, in particular, has become a key platform for political presentation (Jungherr, 2016) and has altered traditional campaigning styles in ways that benefit marginalized groups through an emphasis on likability (Fountaine, 2017). Jungherr (2016) found that that the gender of candidates does not influence Twitter usage. Wagner et al. (2017) found that women, as disadvantaged candidates, are more likely to use Twitter in their campaigns. Evans and Clark (2016) found that women candidates are more likely than men to attack their opponents, tweet about policy issues in general, and women's issues in particular.

Previous research has found that social media personalization also differs for men and women candidates. "Personalization" is multifaceted, but generally refers to candidates' self-disclosure to voters (Meeks, 2017). It emphasizes "personal narrative over abstract policy discussions" (Lawrence et al., 2016: 193). Men candidates tend to personalize more than women (McGregor et al., 2017) and benefit from the personalization strategy more than women (Meeks, 2017). Studies have found that personalization is "the classic double bind" for women, as stereotypical gender self-presentations can be risky and makes a candidate appear "incompetent" (Meeks, 2017: 7; Lawrence et al., 2016; McGregor, 2018). This research emphasizes comparisons between men and women candidates, and contrasts men's more "agentic" (leadership and confident) traits with women's more "communal" (caring and collaboration) ones (Lawrence et al., 2016; McGregor, 2018; Meeks, 2017). It finds that men's selfdisclosure is viewed more positively than women's (Meeks, 2017), suggesting that they have a broader range of self-presentation options. However, when races are competitive, women tend to utilize personalization, especially emphasizing their caregiving roles (McGregor et al., 2017). "Strategic stereotype theory" suggests that candidates draw on gender stereotypes that provide them benefits (Fridkin and Kenney, 2015). For women, this could involving strategically drawing on stereotypes that women are caring (Fridkin and Kenney, 2015). In an examination of the 2016 election, McDonnell (2020) found that both Trump and Clinton both conformed to, and defied, gender stereotypes in the Twitter posts. For example, Clinton Tweets expressed "a more masculine linguistic style, but also a greater number of cooperative words, which are stereotypically associated with feminine speech" (McDonnell, 2020: 71). Although this body of research emphasizes that women candidates can counteract gender stereotypes (e.g. Lawrence et al., 2016; Meeks, 2017), it tends to focus on gender dichotomies and does not examine a full range of gender self-presentations. An exception is Lawrence and her collaborators $(2016: 203,197)$, 
whose study of three women candidates found a "hybridized" and "diverse strategic deployment of femininity," some of which was traditional and some of which challenged traditional gender roles.

Within Twitter, users are given exactly 160 characters for a personal "Twitter bio." While there are many different approaches, writing a series of self-labels has become a common convention. Hillary Clinton was one of the first and notable women candidates to develop such a Twitter bio, using the following labels: 'Wife, mom, lawyer, women \& kids advocate, FLOAR, FLOTUS, US Senator, SecState, author, dog owner, hair icon, pantsuit aficionado, glass ceiling cracker, TBD..." (Ungerleider, 2013). In her 2016 presidential run, she kept most of her Twitter bio, but added "2016 presidential candidate." Research on membership categorization devices has taken different approaches to the conversational use of gendered membership labels like these. Some scholars have argued that gendered labels such as "woman" should not be understood to be inherently gendered (Kitzinger, 2007; Schegloff, 2007). That is, terms like "woman" may be used with other goals in mind, without reference to gender itself (Kitzinger, 2007; Schegloff, 2007). Although conversation analysis has questioned the idea that gendered terms always refer to gender, political candidates' self-presentations are likely to differ from this perspective. In countries with very few women in political office, candidates have great difficulty escaping gendered evaluations on the part of voters and the media (Dittmar, 2015). For example, Clinton received some criticism about the prominent placement of "wife;" feminist activist Chimamanda Ngozi Adiche expressed frustration that the first woman to run for president of the United States labeled herself "wife" before all else (Adebayo, 2018). As a result, candidates' self-presentations differ from those studied in conversational analysis, as they rely on media consultants and campaign managers to carefully craft their self-presentations in order to achieve their political aims (Dittmar, 2015). In fact, the controversy over Clinton's Twitter bio demonstrates the weight and importance that a Twitter bio can carry for women candidates.

In this paper, we focus on the 2020 Democratic primary candidates for U.S. president. The Democratic party platform prioritizes fighting inequality and social justice issues (Democrats.com, 2020), while the Republican platform is rooted in individual rights and creating a small government (GOP.com, 2020). The Democratic party platform defines itself as "the party of inclusion" and its website catalogs its support of diverse racial and ethnic groups, particularly minority groups, as well as women, people with disabilities, union members, and the LGBTQ community (Democrats.com, 2020). Because of this emphasis on diversity and social justice, Democratic candidates may have flexibility in their gender self-presentations. The 2018 midterm election suggests that the 2016 presidential election may have galvanized women to vote for Democratic candidates. However, considered historically, the gender gap in presidential elections began in 1980, as women have been more likely than men to vote Democratic (Arnold, 2020). According to Cascio et al. (2020), women's shift toward the Democratic party has been driven by party positions, as the Republican party moved closer towards "traditional" gender roles since the 1980s, particularly its stance on abortion.

In contrast to prior work that emphasizes gender dichotomies, we develop a more complex and nuanced typology of self-presentation that can be applied to future elections. In the analysis that follows, we ask the following research questions: how do Democratic presidential candidates in 2020 present gender in their campaign websites and Twitter bios? To what extent do these self-presentations fit into gender traditional, neutral, nontraditional and feminist perspectives? How do these self-presentations vary by the gender of the candidate? Finally, what are the implications of gender differences in self-presentation?

\section{METHODS}

We conducted a qualitative study of owned digital platforms, specifically campaign websites and Twitter bios, for the 2020 Democratic primary candidates who qualified for the Democratic party debate in October 2019. We examined candidate accounts that were live in September and October 2019. Although other aspects of the websites reveal how the candidates represent particular issues in their campaigns, we focus our analysis on the website bios, which contain the most information about self-presentation. We also examine candidates' personal Twitter bios, as these have become their primary campaign account. This approach reflects social change in the use of Twitter for political candidates. During Obama's 2008 campaign for president, he tweeted from the account @BarackObama. During Obama's presidency, the official presidential Twitter handle (@POTUS) was created and utilized. In contrast, Donald Trump pioneered the use of a personal Twitter account (@realDonaldTrump) while in political office. The Democratic presidential candidates have all chosen to use their personal Twitter accounts for the 2020 campaign.

For the Twitter bios, we used each label as our unit of analysis. For the candidate websites, we used each sentence as our unit of analysis. Each data source was coded by two researchers and disagreements in coding were discussed and resolved. Due to the short nature of the Twitter bios, we created a simple yes-no classification to evaluate whether or not each candidate used labels that fit into each style of self-presentation on the spectrum. For the websites, which contain more text, we were able to complete a more comprehensive analysis. We counted all 
Table 1. Summary of Spectrum of Gender Self-Presentations

\begin{tabular}{|c|c|c|c|c|}
\hline & Gender Traditional & Gender Neutral & $\begin{array}{l}\text { Gender } \\
\text { Nontraditional }\end{array}$ & Feminist \\
\hline Women & $\begin{array}{l}\text { Stereotypical feminine } \\
\text { gender roles, such as } \\
\text { caretakers and family- } \\
\text { oriented }\end{array}$ & $\begin{array}{l}\text { Gender blind } \\
\text { perspectives, } \\
\text { accomplishments or } \\
\text { policy positions }\end{array}$ & $\begin{array}{l}\text { Stereotypical masculine } \\
\text { gender roles, language or } \\
\text { traits, such as swearing, } \\
\text { toughness and "fighters" }\end{array}$ & $\begin{array}{l}\text { Focus on women's social and } \\
\text { political interests as women, women's } \\
\text { political issues, an awareness of } \\
\text { gender inequalities and patriarchy }\end{array}$ \\
\hline Men & $\begin{array}{l}\text { Stereotypical masculine } \\
\text { gender roles, language or } \\
\text { traits, such as toughness } \\
\text { and "fighters" }\end{array}$ & $\begin{array}{l}\text { Gender Blind } \\
\text { perspectives, } \\
\text { accomplishments or } \\
\text { policy positions }\end{array}$ & $\begin{array}{l}\text { Stereotypical feminine } \\
\text { gender roles, such as } \\
\text { caretakers and family- } \\
\text { oriented }\end{array}$ & $\begin{array}{l}\text { Focus on women's social and } \\
\text { political interests as women, women's } \\
\text { political issues, an awareness of } \\
\text { gender inequalities and patriarchy }\end{array}$ \\
\hline
\end{tabular}

Table 2. Women's Self-Presentations on Twitter

\begin{tabular}{lcccc}
\hline Candidate's Name & Gender Traditional & Gender Neutral & Gender Nontraditional & Feminist \\
\hline Tulsi Gabbard & $\mathrm{N}$ & $\mathrm{Y}$ & $\mathrm{Y}$ & $\mathrm{N}$ \\
\hline Kamala Harris & $\mathrm{Y}$ & $\mathrm{Y}$ & $\mathrm{Y}$ & $\mathrm{Y}$ \\
\hline Amy Klobuchar & $\mathrm{N}$ & $\mathrm{Y}$ & $\mathrm{N}$ & $\mathrm{N}$ \\
\hline Elizabeth Warren & $\mathrm{Y}$ & $\mathrm{Y}$ & $\mathrm{Y}$ & $\mathrm{Y}$ \\
\hline Percent (n) & $50 \%(2)$ & $100 \%(4)$ & $75 \%(3)$ & $50 \%(2)$ \\
\hline
\end{tabular}

$* \mathrm{~N}=$ No (not present); $\mathrm{Y}=$ Yes (present)

of the self-presentations on each website, keeping in mind that each sentence could contain multiple selfpresentations on the spectrum. However, only 32 out of 811 sentences (3.9 percent) were classified in multiple ways. As we will explain, the categories on the spectrum are not mutually exclusive and most candidates drew on multiple self-presentation approaches.

The analysis of the data started inductively with open coding for major themes. That is, these modes of selfpresentation emerged from the candidate websites and Twitter bios. We used qualitative data analysis methods to enter codes, highlight passages of text, and examine co-occurrences of codes. The coding scheme and analytical framework was continually refined throughout the analytic process (Miles and Huberman, 1994). This strategy sought to compare quotes from multiple websites on a given theme. As we developed codes inductively, we then analyzed our existing codes in light of previous theories of gender and feminist consciousness and identity. As we progressed to a more fine-grained coding system, we developed a typology or spectrum of self-presentation that drew on previous theories. We then went back to the data to further refine our typology and codes. This iterative process ensured that our spectrum was built inductively from the data, while also being compared to existing theory.

In their classic work, Ferree and Hess (1994: 131) define gender consciousness as "politicized consciousness or identification of women as a group with common interests and a collective identity as women." Research that builds on this work posits that women can be classified on a continuum of consciousness and identification, ranging from traditional on one side to feminist on the other (Aronson, 2017). Starting with these two ends of a continuum, traditional and feminist, we developed a typology that represented multiple points on a gender selfpresentation spectrum. In particular, we classified self-presentations according to a full spectrum of possible approaches: traditional, neutral, nontraditional, or feminist (See Table 1). In the analysis that follows, we begin by examining each of the gender self-presentations, comparing women and men. Our spectrum advances understandings of gender and elections at a pivotal time in politics. Rather than simple dichotomies that reify gender binaries, our analysis of the candidates suggests a more complex, nuanced theoretical framework.

\section{FINDINGS}

\section{Traditional Self-Presentations}

On one side of the spectrum, we find traditional self-presentations (See Table 1). For women, this approach emphasizes their roles within the domestic sphere or family care, such as highlighting their status as wives and mothers. For men, traditional masculine identity is presented in terms of strength, independence, leadership, courage and traditional masculine workplace roles, such as the military. Considering Twitter bios, half of the women $(\mathrm{n}=2)$ and one-quarter of the men $(\mathrm{n}=2)$ used gender traditional self-presentations (See Tables 2 and 4). Considering website bios, just 3.2 percent ( $n=9$; see Table 3 ) of women's and 7.2 percent $(n=38$; see Table 5) of men's sentences featured self-presentations that were traditional. Together, these findings suggest that while traditional self-presentations are used, their prevalence is minimal. Thus, these candidates seek to de-emphasize traditional gender roles in favor of other approaches. 
Table 3. Women's Self-Presentations on Websites

\begin{tabular}{lccccc}
\hline $\begin{array}{l}\text { Candidate's } \\
\text { Name }\end{array}$ & Traditional & Neutral & Nontraditional & Feminist & $\begin{array}{c}\text { Total Self-Presentations } \\
\text { for each Candidate (n) }\end{array}$ \\
\hline Tulsi Gabbard & $0 \%(0)$ & $72.9 \%(70)$ & $21.9 \%(21)$ & $5.2 \%(5)$ & $100 \%(96)$ \\
\hline Kamala Harris & $.08 \%(1)$ & $46.3 \%(57)$ & $39 \%(48)$ & $13.8 \%(17)$ & $100 \%(123)$ \\
\hline Amy Klobuchar & $3.7 \%(1)$ & $81.5 \%(22)$ & $7.4 \%(2)$ & $7.4 \%(2)$ & $100 \%(27)$ \\
\hline Elizabeth Warren & $17.9 \%(7)$ & $69.2 \%(27)$ & $12.8 \%(5)$ & $0 \%(0)$ & $100 \%(39)$ \\
\hline Total Percent (n) & $3.2 \%(9)$ & $61.8 \%(176)$ & $26.7 \%(76)$ & $8.4 \%(24)$ & $100 \%(285)$ \\
\hline
\end{tabular}

Table 4. Men's Self-Presentations on Twitter

\begin{tabular}{lcccc}
\hline Candidate's Name & Gender Traditional & Gender Neutral & Gender Nontraditional & Feminist \\
\hline Joe Biden & $\mathrm{N}$ & $\mathrm{Y}$ & $\mathrm{Y}$ & $\mathrm{N}$ \\
\hline Cory Booker & $\mathrm{N}$ & $\mathrm{Y}$ & $\mathrm{N}$ & $\mathrm{Y}$ \\
\hline Pete Buttigieg & $\mathrm{Y}$ & $\mathrm{Y}$ & $\mathrm{Y}$ & $\mathrm{Y}$ \\
\hline Julian Castro & $\mathrm{N}$ & $\mathrm{Y}$ & $\mathrm{N}$ & $\mathrm{Y}$ \\
\hline Beto O'Rourke & $\mathrm{N}$ & $\mathrm{Y}$ & $\mathrm{N}$ & $\mathrm{N}$ \\
\hline Bernie Sanders & $\mathrm{N}$ & $\mathrm{Y}$ & $\mathrm{Y}$ & $\mathrm{N}$ \\
\hline Tom Steyer & $\mathrm{N}$ & $\mathrm{Y}$ & $\mathrm{N}$ & $\mathrm{Y}$ \\
\hline Andrew Yang & $\mathrm{Y}$ & $\mathrm{Y}$ & $50 \%(4)$ & $\mathrm{N}$ \\
\hline Percent (n) & $25 \%(2)$ & $100 \%(8)$ & & $50 \%(4)$ \\
\hline
\end{tabular}

* $\mathrm{N}=$ No (not present); $\mathrm{Y}=$ Yes (present)

Table 5. Men's Self-Presentations on Websites

\begin{tabular}{lccccc}
\hline $\begin{array}{l}\text { Candidate's } \\
\text { Name }\end{array}$ & Traditional & Neutral & Nontraditional & Feminist & $\begin{array}{l}\text { Total Self-Presentations } \\
\text { for each Candidate (n) }\end{array}$ \\
\hline Joe Biden & $2.1 \%(2)$ & $72.6 \%(69)$ & $17.9 \%(17)$ & $7.4 \%(7)$ & $100 \%(95)$ \\
\hline Cory Booker & $31 \%(13)$ & $59.5 \%(25)$ & $0 \%(0)$ & $9.5 \%(4)$ & $100 \%(42)$ \\
\hline Pete Buttigeg & $9.8 \%(5)$ & $80.4 \%(41)$ & $2 \%(1)$ & $7.8 \%(4)$ & $100 \%(51)$ \\
\hline Julian Castro & $1.8 \%(1)$ & $60.7 \%(34)$ & $0 \%(0)$ & $37.5 \%(21)$ & $100 \%(56)$ \\
\hline Beto O'Rourke & $6.6 \%(10)$ & $79.5 \%(120)$ & $9.3 \%(14)$ & $4.6 \%(7)$ & $100 \%(151)$ \\
\hline Bernie Sanders & $10 \%(5)$ & $68 \%(34)$ & $10 \%(5)$ & $12 \%(6)$ & $100 \%(50)$ \\
\hline Tom Steyer & $5.7 \%(2)$ & $80 \%(28)$ & $5.7 \%(2)$ & $8.6 \%(3)$ & $100 \%(35)$ \\
\hline Andrew Yang & $0 \%(0)$ & $52.2 \%(24)$ & $8.7 \%(4)$ & $39.1 \%(18)$ & $100 \%(46)$ \\
\hline Percent (n) & $7.2 \%(38)$ & $71.3 \%(375)$ & $8.2 \%(43)$ & $13.3 \%(70)$ & $100 \%(526)$ \\
\hline
\end{tabular}

\section{Women's traditional self-presentations}

As Table 2 illustrates, half of the women used gender traditional self-presentations in their Twitter bios. For example, in her Twitter bio in June 2019, Elizabeth Warren labeled herself "former teacher \& law professor," "wife," "mom," and "grandmother." In October 2019, Warren changed her "former teacher \& law professor," labels to a "former teacher, and candidate for president." While at first glance, some of these labels appear traditionally feminine, there is a subtext that also shows a nontraditional side. The occupation of a "teacher" has historically been seen as a feminine profession. However, in addition to teaching elementary school children with disabilities (which would follow traditional gender roles), Warren was subsequently a professor specializing in bankruptcy law. The latter represents a gender-nontraditional field for women, especially in the era in which she worked in this capacity. Although the removal of the "law professor" label may indicate that she sought to obscure this nontraditional role, the addition of the "candidate for president" label suggests an attempt to blend traditional and nontraditional labels.

Warren was the only candidate to use the title "grandmother" in her Twitter bio. It is also interesting to note that her traditional labels "wife," "mom," and "grandmother" come secondary to her professional labels "Senator" and "candidate for president." Kamala Harris used a similar mix of traditional and nontraditional labels in her Twitter bio. She named herself "wife" and "Auntie," all traditionally feminine roles. Yet these gender labels are sandwiched between her career labels, including "senator," "candidate for president," and her nontraditional promise, "fighting for the people." The order and content of the labels suggests that both Warren's and Harris' self-presentations attempt to blend different approaches: although they include traditional gender labels, their bios de-emphasize them.

Turning to the websites, we find that traditional self-presentations were the least popular approach among the women (only 3.2 percent--n=9--of self-presentations feature a traditional perspective; See Table 3). Considering the proportion of traditional self-presentations on websites, there was a range from 0 on the low end (Tulsi 
Gabbard) to 17.9 percent on the high end (Warren; See Table 3). Considering the percentage distributions, the white candidates, (Klobuchar and Warren), had a larger proportion of traditional self-presentations than the two candidates of color (Gabbard and Harris; see Table 3).

Many of the candidates mention their immediate family on their websites, including their husbands, children, stepchildren and/or grandchildren. For example, Warren stated: "Elizabeth and her husband Bruce have been married for 38 years. They have three grandchildren and a golden retriever named Bailey." Here, she mentioned the length of time that she has been married and draws attention to her status as a grandmother. The longevity of her marriage establishes Warren's good character and emphasizes the ways that she is reliable and consistent. This rhetorical construction conjures up an image of someone who will be long-term and sustainable in politics as well. Mentioning her grandchildren serves to highlight her approach to creating a positive future. References to her dog, who himself became a feature of her campaign, helps to establish her credibility as ordinary and relatable. Similarly, Harris talked about her husband and stepchild: "She is married to Doug Emhoff and a stepmother to Ella and Cole Emhoff." Likewise, Gabbard emphasized religious and racial diversity in her family as a strength when she said: "Tulsi's interfaith, interracial family is a reflection of the story of America, which taught her to accept and embody diverse perspectives and identities." These websites all illustrate the ways in which the women candidates emphasize their family roles and the importance of family in their lives. This emphasis also seeks to provide a personal connection to voters by using details from their family lives to humanize them and make them more relatable (See also Lawrence et al., 2016; McGregor, 2018; Meeks, 2017). Thus, women draw on traditional selfpresentations, but sometimes do so in new ways.

\section{Men's traditional self-presentations}

Men's traditional self-presentations were represented through their display of stereotypical masculine gender roles, including masculine language or traits, such as using the word "fighter," swearing, or emphasizing their toughness or military experience. Overall, one-quarter of the men ( $n=2$, see Table 4) used gender traditional selfpresentations in their Twitter bios. For example, Andrew Yang described himself as an "entrepreneur" and "founder of Venture for America." His emphasis on success in business is a historically male-dominated field. Similarly, Pete Buttigieg described himself as an "Afghanistan vet" and "businessman." As we will explain later, while Buttigieg included a blend of traditional and nontraditional labels in his profile, his military service and business experience underscored his masculine self-presentation.

Only 7.2 percent ( $n=38$; See Table 5) of men's website self-presentations took a traditional approach, making it the least utilized form of self-presentation. For example, Cory Booker stated: "As mayor, Cory took on some of the city's biggest challenges-figting to curb crime, reinvigorating a dwindling local economy, and raising morale across the city ..." (emphasis ours). Similarly, Bernie Sanders discussed his tough stance on policy, also using the word "fight" when he said that he would "Fight for comprehensive immigration reform to create a fair and humane immigration system" (emphasis ours). Buttigieg emphasized his previous career with the military and the impact it will have on his policy decisions: "Pete served as a lieutenant in the U.S. Navy Reserve and took an unpaid sevenmonth leave during his mayoral term to deploy to Afghanistan. For his counterterrorism work, he earned the Joint Service Commendation Medal." Buttigieg was the only male candidate with military service experience and this description fits with stereotypically masculine work experiences. Thus, gender traditional self-presentations for men emphasized traditionally masculine roles in stereotypical ways. In contrast, the women's traditional selfpresentations often put a new twist on their traditional family roles by blending them with other types of selfpresentation. This finding provides some evidence that women's self-presentations were more multifaceted than men's.

\section{Neutral Self-Presentations}

In the middle of the spectrum of self-presentations, candidates emphasized gender neutral perspectives. Here, they downplayed gender, displayed a gender-blind approach, and focused on gender-neutral accomplishments or policy positions. This form of self-presentation was the most common in both the Twitter bios and the website bios for both male and female candidates. In the Twitter bios, all of the candidates included gender neutral labels (See the highlighted cells in Tables 2 and 4). One woman (Klobuchar) and two men (Sanders and Beto O'Rourke) chose to use solely gender blind labels in their Twitter bios. In website bios, a gender neutral approach was present for all of the women (61.8 percent of their self-presentations; $n=176$; See Table 3) and men (71.3 percent of their self-presentations; $n=375$; See Table 5). These gender neutral approaches are thought to have the most widespread voter appeal.

\section{Women's neutral self-presentations}

Amy Klobuchar was the only female candidate who uses gender-neutral self-presentations exclusively in her Twitter bio (See Table 2). She labeled herself a "senator" and "candidate for president" and nothing else. This 
serious, straightforward and gender neutral tone aligns with her campaign more generally. Warren used the gender neutral "US Senator" and "candidate for president," although, as we have mentioned, "former teacher," a gender traditional label, was sandwiched between these labels. Harris started her Twitter bio with "U.S. Senator and candidate for president," before describing her traditional roles. In contrast, Gabbard began her bio with nontraditional labels and ended it with the neutral: "Congress. Candidate for President." Thus, although all of the candidates utilized gender neutral self-presentations in their Twitter bios, the presence of other labels and the order in which they appear suggest that candidates varied in their self-presentation.

Like the Twitter bios, all of the women used neutral self-presentations on their websites most frequently (See Table 3). Candidates featured lengthy paragraphs about gender neutral accomplishments during their political careers or discussed their policy positions. For example, Warren emphasized her leadership experience: "During the 2008 financial crisis, Democratic Majority Leader Harry Reid asked Elizabeth to serve as Chair of the Congressional Oversight Panel to provide some oversight of TARP, the Wall Street bailout." Similarly, Gabbard described her significant accomplishments at a young age: "she campaigned for and was elected to the Hawaii State House of Representatives when she was 21 years old." This gender neutral accomplishment highlighted Gabbard's age rather than gender. Harris highlighted her policy accomplishments on her website: "She helped thousands of families stay in their homes and passed one of the nation's strongest anti-foreclosure laws." In addition, the candidates focused on educational attainment as another type of gender-neutral accomplishment. For example, Harris emphasized her education on her website: "Born in Oakland, Kamala Harris is a graduate of Howard University. She earned her law degree from the University of California, Hastings College of the Law." Together, these examples focus on merit and illustrate the extent to which these women were qualified for political leadership through their accomplishments.

\section{Men's neutral self-presentations}

Considering the men's Twitter bios, Sanders and O'Rourke chose a completely gender-neutral emphasis (See Table 4). Like Klobuchar, Sanders simply used "senator" and "candidate for president" to describe himself. O'Rourke also fell into this category because he chose to present no self labels in his Twitter bio. In his unique profile, O'Rourke writes: "building a new kind of politics through a grassroots campaign for America - for everyone in America." Other men blended gender neutral and other approaches in their Twitter bios (See Table 4). For example, Booker took a gender-neutral focus, using "senator" and "candidate for president." However, Booker also identified his gender pronouns, "he/him," which, as we explain later, is classified as a feminist Twitter bio label. Similarly, Joe Biden begins with the gender neutral "Senator, Vice President, 2020 candidate for President of the United States," and then, as we analyze later, moved on to several gender nontraditional labels. In all, like the women, the men emphasized gender neutral Twitter bios and place them prominently at the beginning of their bio.

Turning to the websites, the men had a large proportion of gender neutral self-presentations (See Table 5). It is interesting to note that the men of color had a lower proportion of neutral self-presentations than the white men (See Table 5). In particular, Yang, who is Twiwanese American, had the lowest proportion of neutral statements, at 52.2 percent. This was followed by Booker, who is African American (59.5) and Castro, who is Latinix (60.7 percent). In comparison, white candidates had neutral self-presentations that ranged from 68 percent (Sanders) to 80.4 percent (Buttigeg).

For example, Tom Steyer wrote of his achievements: "In 2013, he founded NextGen America, a nonprofit group that combats climate change, promotes social justice and increases participation in our democracy through voter registration and grassroots organizing." Similarly, Buttigieg talked about his successful political career: "Pete is in his eighth and final year as Mayor of South Bend, Indiana. Pete was first elected mayor in 2011 at only 29 years old and re-elected in 2015 with 80 percent of the vote." The latter sentence emphasizes not gender, but electoral accomplishment despite his young age. Like the women, men also emphasized their educational attainment. Yang, for example, discussed his Ivy League education: "I studied economics and political science at Brown and went to law school at Columbia." Similarly, O’Rourke mentioned his Ivy League education, yet he framed it in terms of social class disadvantage, as he took out loans to pay for college. As he put it, "After graduating from high school, he took out student loans and moved to New York City to attend Columbia University, where he was a co-captain of the crew team and majored in English Literature." Thus, the majority of self-presentations on the websites were presented in a gender neutral way that emphasized the merit of the candidate.

\section{Nontraditional Self-Presentations}

At the next point on the spectrum, we find that candidates present themselves in gender nontraditional ways (See Table 1). In both the Twitter bios and websites, women were more likely to take a gender nontraditional approach than men. Half of the male candidates and 75 percent of the female candidates presented nontraditional gender labels in their Twitter bios (See Tables 2 and 4). On websites, women took this approach more frequently 
than men ( 26.7 percent, $n=76$ of the women's self-presentations, compared to 8.2 percent, $n=43$ of the men's; see Tables 3 and 5). Additionally, the content of the nontraditional self-presentation differed. For women, this approach included taking a nontraditional stance on the traditional role of motherhood, using stereotypically masculine language, and nontraditional gender career experiences. For men, nontraditional self-presentations stayed solely in the domain of fatherhood.

\section{Women's nontraditional self-presentations}

Table 2 illustrates that three of the four women candidates used gender nontraditional labels in their Twitter bios. To differing degrees, all of the candidates except for Klobuchar blended nontraditional and other selfpresentations. Blending allows candidates to break away from traditional female roles and claim masculine language to define themselves. For example, Warren used a very clever nontraditional label in her Twitter bio. She used the frequently-used pattern of the "mom" label, followed by a list of her children's names ("Amelia, Alex, Bailey"). However, she included "@CFPB” as a fourth child of hers. CFPB, the Consumer Financial Protection Bureau is a major piece of legislation that Warren spearheaded. Warren drew on a classic feminine trope of "mom," but added a humorous spin to show a nontraditional self-presentation.

Harris also included nontraditional self-presentations in her Twitter bio. After her neutral labels and the traditional label "wife," she uses "momala," which is the name her stepchildren call her. Harris had been open on the campaign trail about her role as a stepmom and her nontraditional family (Harris 2019). Harris also used her Twitter bio to declare she is "fighting for the people" (emphasis ours). The "fighter" label is nontraditional for women. Klein (2019) argues that while "men are assumed to be fighters. ... Women have to overcome suspicions of weakness, which means they have to be much more explicit about their willingness to fight."

Gabbard presented the most nontraditional self-presentation of the women in her Twitter bio. She did not mention family in any capacity and instead lists "soldier" as her first label, representing her tour in Iraq from 20042005 and in Kuwait from 2008-2009. She also labeled herself "veteran" and "surfer," the latter of which acknowledges her Hawaian roots. Unlike the other women who used a blend of presentations, Gabbard sticks with only neutral and nontraditional self-presentations.

All of the women drew on nontraditional website self-presentations, although their usage ranges from $7.4(\mathrm{n}=2$, Klobuchar) to 39 percent ( $\mathrm{n}=48$, Harris; See Table 3). Although we have seen that white women more frequently drew on traditional self-presentations on their websites, women of color had a high proportion of nontraditional website self-presentations than white women (See Table 3). Gabbard, with 21.9 percent of her self-presentations classified as nontraditional, describes her multi-ethnic and multi-faith family origins as follows: "A practicing Hindu, she is of Asian, Polynesian, and Caucasian descent." Harris, who identifies as African American and Indian, had 39 percent of her self-presentations classified as nontraditional. These proportions contrast with those of Klobuchar (7.4 percent) and Warren (12.8 percent), who are both white.

In website self-presentations, women used stereotypically masculine language, such as swearing or words like "fight" to describe their approach to politics. As already mentioned, these self-presentations were classified as traditional for the men. Nontraditional career experiences, such as work history in traditionally male occupations, were also included in this type of self-presentation. With the rise of women in politics--including their successes in the 2018 election and the number of women running for the Democratic nomination for president in 2020-women candidates were expressing themselves in unprecedented ways (Aronson, Oldham and Lucas, Under Review). That is, we are in a new era of self-presentation with women candidates moving in a new direction.

Harris, who had the highest proportion of nontraditional self-presentation (at 39 percent) states: "Throughout her career, Kamala has been a fearless advocate for the voiceless and vulnerable and a vocal and determined fighter on behalf of all people" (emphasis ours). In fact, all of Harris' nontraditional self-presentations centered on emphasizing her "fighter" stance to politics. Likewise, Klobuchar also used the word "fight" to talk about her policy positions and her persistence: "And she's been fighting her whole life to bring down the cost of prescription drugs" (emphasis ours).

Warren emphasized her nontraditional educational path as follows: "When [daughter] Amelia turned two, Elizabeth enrolled in a public law school that cost $\$ 450$ a semester. Three years later, she graduated at eight months pregnant with her son Alex." This website self-presentation illustrated a nontraditional educational achievement during the 1970s. It is not only exceptional, but also gender nontraditional, that Warren was able to complete a law degree as a pregnant mother of a very young child. Although this example mentions motherhood and pregnancy, it turns gender traditionality on its head by linking these feminine roles with the nontraditional educational achievement of law school during a time when very few women attended.

Gender nontraditional self-presentations also included the "tough" self-presentation of Gabbard, who campaigned as a Major in the National Guard. Her military experience represents a traditionally masculine career path. As she stated: "Tulsi came home [from Iraq], forever changed, committed to fighting for peace and an end to regime change wars. Between her two tours of duty in the Middle East, Tulsi worked in the U.S. Senate as a legislative 
aide to Senator Danny Akaka, where she focused on veterans' issues. ... At 31 years old, Tulsi ran for Congress. ... Holding close the memories of her fellow veterans and the sacrifices made by her friends, she was focused on her mission and knew she could not wait" (emphasis ours).

With its focus on her military experiences, Gabbard's self-presentation was the most nontraditional. In sum, the majority of women candidates drew on nontraditional self-presentations in both their Twitter bios and their websites and did so in a wide range of ways. In doing so, they illustrate a new era of campaigning as a woman.

\section{Men's nontraditional self-presentations}

Men were less likely than women to utilize gender nontraditional self-presentations in their Twitter bios, although half did so (see Tables 2 and 4). Of the men, Biden's Twitter bio carries the largest number of nontraditional labels. He described himself as "husband to @DrBiden," tagging his wife and acknowledging her doctorate in education. He also emphasised his family roles with "proud father and grandfather" labels. Biden places these nontraditional labels after the gender neutral ones, "Senator, Vice President, 2020 candidate for President of the United States." His bio concluded on a gender neutral, but humorous, note: "Loves ice cream, aviators and @Amtrack." Showing the importance of family, Julian Castro also listed his gender nontraditional labels before his traditional labels. He started his bio with "Father, husband," and then went into gender neutral "Texan, presidential candidate." Steyer also listed his family labels first, with "husband \& father" preceding the more traditional label of "former investor."

The men used a nontraditional approach to websites at one of the lowest rates, at just 8.2 percent $(n=43)$ of their website self-presentations (See Table 5). Biden, with the highest percentage (17.9 percent) on his website, provides very personal accounts of his struggles through family tragedy. He discussed the adversity he faced after the tragic deaths of his wife Neilia and daughter Naomi after a car accident that also injured his two sons: "Joe is sworn into the U.S. Senate at his sons' hospital bedsides, and begins commuting from Wilmington to Washington every day, first by car and then by train, in order to tuck his sons in bed at night and see them get up in the morning. He will continue to do so throughout his time in the Senate. For five years, Joe raises Beau and Hunter as a single father, with the help of his sister Valerie and his family." This self-presentation contains a great deal of personalization, as it involves emotional appeals to allow voters to identify with Biden's vulnerability and humanity (Meeks, 2017). This approach benefits men more than women (Meeks 2017). Furthermore, Biden's self-presentation emphasized his traditionally feminine role as a single father, his description also emphasized his commitment to his role as Senator.

Yang also discussed his role as a father on his website and emphasized the way that his vision for the future involves creating a better country for his boys. He said: "I'm the father of two young boys. I know the country my sons will grow up in is going to be very different than the one I grew up in, and I want to look back at my life knowing I did everything in my power to create the kind of future our children deserve." Similarly, O'Rourke talked about getting married to his wife and listed the names and ages of his three children: "On September 24, 2005, Beto and Amy became husband and wife. A year later, Ulysses O'Rourke (age 12) was born-followed soon by Molly (age 11) and Henry (age 8). They attend the same public school Beto went to as a kid." Here, O’Rourke focused on the roots he built in his home community, where his children will also be raised. In addition to highlighting family, this approach is nontraditional because it is often expected that ambitious men will follow job opportunities rather than remain in their own hometown.

Thus, although men used nontraditional self-presentations less often than other types, when they did so, it was quite meaningful; they described fatherhood tragedy, wanting the best for their children, and proudly introducing their family members. Although men's nontraditional self-presentations included family-orientations that focus on their status as fathers, it is important to note that they did not go beyond the fatherhood role in their nontraditional self-presentations. In keeping their nontraditional self-presentations on fatherhood, they highlight a protectionist stance that seeks to make voters feel protected. As we have seen, women's nontraditional self-presentations are more diverse.

\section{Feminist Self-Presentations}

On the most progressive side of the spectrum, candidates used explicitly feminist self-presentations. Feminist self-presentations are classified as such because they emphasize women's social and political interests as women and/or include an awareness of gender inequalities and patriarchy (Aronson, 2017). Women and men were equally likely to include feminist labels in their twitter bios (at 50 percent; see Tables 2 and 4, while men were more likely than women to utilize feminist website self-presentations ( 13.3 percent, $\mathrm{n}=70$ and $8.4 \%, \mathrm{n}=24$, respectively).

\section{Women's feminist self-presentations}

While no candidates had overt feminist labels in their Twitter bios, six of the candidates (two women and four men; see Tables 2 and 4) included their gender pronouns. Warren and Harris were the only two women who listed 
the pronouns "she/her." We classify this label as a feminist self-presentation because it aligns with feminist approaches to gender and signals support of LGBTQ+ issues.

Overall, 8.4 percent $(\mathrm{n}=24)$ of the women's website self-presentations are classified as feminist, with a range from 0 (Warren) to 13.8 percent (Harris; See Table 3). Typically, candidates emphasized women's issues in their policy positions. For example, Klobuchar stated her stance on domestic violence: "She is also the author of a proposal that would close what is commonly referred to as the 'boyfriend loophole' by preventing people who have abused dating partners from buying or owning firearms." Likewise, Harris stated her policy positions concerning women's rights: "As California's Attorney General, Kamala prosecuted transnational gangs that exploited women and children and trafficked in guns and drugs. She led comprehensive studies and investigations into the impacts of transnational criminal organizations and human trafficking." All of the women candidates, with the exception of Warren, focused on their social and political interest as women by taking a stance on legislation that affects women.

Harris also illustrated a feminist representations in her emphasis as a pathbreaking Senator. As she put it, "In 2017, Kamala D. Harris was sworn in as a United States Senator for California, the second African-American woman and first South Asian-American Senator in history." This emphasis on intersectionality was also common in the 2018 election, as women Congressional candidates' websites featured being the "first" woman elected from a particular ethnic or racial background or religion (Aronson, Oldham and Lucas, Under Review). The intersection of gender with racial or ethnic identities is an important element of feminist self-presentation.

\section{Men's feminist self-presentations}

Like the women, half $(n=4)$ of the men listed their gender pronouns in their Twitter bios. Booker, Buttigieg, and Steyer all included "he/him" in their bios. Castro included "he/him/el" which emphasizes the intersection of his identity as male and Hispanic. While simultaneously confirming or reinforcing their male identity, including gender pronouns in their Twitter bio shows awareness of this social issue and emphasizes support for LGBTQ+ issues. In addition to listing his pronouns, Buttigieg also stated: "husband to Chasten." As the first openly gay candidate to run for president, labelling himself in this way illustrates both his personal interests and policy stance on LGBTQ+ issues in this feminist self-presentation. Buttigieg's husband Chasten is a vocal and active spouse on Twitter, with nearly 400,000 followers.

In our study of websites, we find that men candidates' self-presentations focused on women's issues 13.3 percent of the time $(n=70)$, which is a greater proportion than women's feminist self-presentations. As Democrats, men may feel pressured to show voters that they are progressive and concerned with women's issues. This approach is especially the case when they are running against women, who may be perceived by voters as having an advantage on women's issues (Dittmar, 2015).

Although the men focus on women's issues at a higher rate than the women themselves, they did so in a traditionally masculine way. For example, in an interesting linguistic strategy, Castro stated that he will: "Protect victims of domestic violence, sexual assault, and human trafficking . . ." (emphasis ours). Here, Castro simultaneously emphasized the importance of women's issues while conjuring up images of male protection of vulnerable women. Like Castro, Sanders fused traditional and feminist self-presentation by using masculine language when explaining women's reproductive rights: "We must fight back together, and defend a woman's right to control her own body and economic future" (emphasis ours). Thus, men often presented women's issues in ways that also signal their masculine qualities to voters.

As the first openly gay presidential candidate, Buttigieg's statement about his family also fell under the feminist self-presentation category. Buttigieg talks about his educational achievements, husband and dogs: "A Rhodes Scholar at Oxford and a graduate of Harvard University, Pete lives with his husband Chasten in the same South Bend neighborhood where he grew up, with their two rescue dogs, Truman and Buddy." By presenting his marriage in this seemingly traditional way--living in the neighborhood where he was raised and emphasizing that his dogs are a part of his family--Buttigieg advances marriage equality as a feminist issue. He also said he will work to: "Close the 'boyfriend loophole' and disarm domestic abusers" (emphasis ours). Although addressing a similar issue as Klobacher, quoted above, Buttigieg's use of the word "disarm" is traditionally masculine. Thus, men emphasized that they will focus on women's issues in their policy decisions in order to be appealing to Democratic voters, who might be drawn to the women candidates (See also Dittmar, 2015). However, men's statements of these issues typically drew on traditionally masculine language ("fight," "defend," and "disarm") or conjured up images of protection of vulnerable women. 


\section{CONCLUSIONS}

The 2020 U.S. Democratic presidential primary was unprecedented in the number of women running. In this article, we push the scholarship on gender and politics forward by examining male and female gender selfpresentations in Twitter bios and candidate websites. Although politics has its own norms regardless of gender, the political sphere is ripe with expectations about how candidates "do gender" in their self-presentations (West and Zimmerman, 1987). In contrast to prior research, which emphasizes gender dichotomies in self-presentation, we argue that gender self-presentations can be classified on a spectrum that includes gender traditional, neutral, nontraditional and feminist self-presentations. Our spectrum provides a new theoretical framework for understanding candidates' gendered self-presentations. This area of research is undertheorized in previous studies of prior eras, yet it will be increasingly important in future elections as women continue to expand their role in politics and push the boundaries of typical self-presentation.

All of the candidates examined here blended gender self-presentations. For women, gender traditional selfpresentations emphasize their family roles, while for men they focus on "tough" language or traditionally masculine careers. Perhaps reflecting the changing social context since Donald Trump's election, gender traditional selfpresentations were the least utilized by both Democratic party men and women. Gender neutral or gender blind self-presentations, the most common approach for both women and men, de-emphasize gender and focus instead on accomplishments or policy positions. All of the candidates feature gender neutral labels in their Twitter bios and over 60 percent of women's, and over 70 percent of men's, website self-presentations were gender neutral. As a political strategy, candidates may think that this approach has the widest voter appeal.

Turning to the two areas that illustrate the greatest social change, we find notable gender differences in both the frequency and content of nontraditional and feminist self-presentations. Women candidates were more likely than men to utilize nontraditional approaches. Seventy-five percent of women's Twitter bios and 26.7 percent of their website self-presentations were nontraditional, compared to 50 percent and 8.2 percent of men's. The content of nontraditional self-presentations also differed. While men only discussed their fatherhood roles, the women were more multifaceted, drawing on masculine language and careers and flipping traditional gender scripts in unusual ways. These findings may suggest that as candidates, women have moved further outside of rigid gender roles than have men.

Considering feminist self-presentations, we find equal prevalence of the use of gender pronouns in Twitter bios (50 percent of both men and women). We also find that men's website bios more frequently mention feminist issues than women's (13.3 percent vs. $8.4 \%$, respectively). Yet when they do so, men emphasized traditionally masculine language or emphasized that they will protect vulnerable women. This finding provides further evidence that female Democratic candidates have broken out of their gender roles in ways that are more visible than the male candidates.

Although a complete intersectional analysis is beyond the scope of this article, we found some racial and ethnic differences in self-presentation on websites. White women candidates were more likely than women of color to emphasize gender traditional self-presentations. In contrast, women of color more frequently than white women drew on gender non-traditional self-presentations. Similarly, men of color were less likely than white men to provide gender neutral self-presentations. Although more research is needed on the intersections of gender and racial and ethnic background, these findings suggest that candidates of color may draw on more diverse and less traditional gender self-presentations than white candidates.

There are several limitations to this study that should be addressed by future research. First, although we have been able to focus in depth on the 2020 Democratic Presidential Primary, we are limited in the number and type of elections considered. Future research should expand the approaches considered to develop a more systematic understanding of gender self-presentations in elections. In particular, it will be important to examine whether these types of self-presentations are unique to the U.S. or are relevant in other countries. Additionally, further research on other types of self-presentation, such as how candidates interact in debates and with supporters on the campaign trail, would allow for further development of these theories of self-presentation. In addition, a historical comparison with previous elections could help untangle the extent to which these self-presentations are unique to 2020. Additionally, although we have moved beyond a dichotomous understanding of gender self-presentation by presenting a continuum, this process may inadvertently reinforce a gender dichotomy. Future research should take care to develop nuanced analyses that move beyond gender comparisons. For example, although our examination has allowed us to consider some intersections between gender, ethnicity, race and sexual orientation, future research should deepen these comparisons. Finally, this analysis captures one moment in time. Since we conducted our research, the Democrats have selected Joe Biden as the 2020 Democratic nominee, and Biden announced in March 2020 he would select a female running mate. Future research should examine how the 2020 general election unfolds and whether gender self-presentation influences the election's outcome. 
Despite these limitations, our findings reinforce other evidence, such as from the 2018 election, regarding transformations of women in politics (See also Aronson and Fleming, Under Review; Aronson, Oldham and Lucas, Under Review). That is, not only are women running for office and getting elected in large numbers, but their gender self-presentations in their campaigns are more diverse than men's. This finding may reflect the new candidates' resistance after Donald Trump's election, as they are challenging norms for women in politics. These candidates are defying expectations and starting to alter our expectations for how women in politics represent themselves, in digital media and beyond.

\section{ACKNOWLEDGEMENTS}

This project was funded by The Institute for Research on Women and Gender at the University of Michigan-Ann Arbor, The National Center for Institutional Diversity at the University of Michigan-Ann Arbor, CEW+ at the University of Michigan-Ann Arbor, and The Office of Research and Sponsored Programs at the University of Michigan-Dearborn. We would like to thank Ronald Aronson and the journal's anonymous reviewers for providing significant feedback on the article. We would also like to thank the Research Assistants who helped conceptualize this project: Matthew Fleming, Grace Bradley, and Destiny Flowers-Fayad.

\section{REFERENCES}

Adebayo, B. (2018). Hillary Clinton has changed her Twitter bio and it does not start with wife. CNN. https://www.cnn.com/2018/04/24/africa/chimamanda-adichie-hillary-clinton-wife-africa/index.html

Arnold, L. (n.d.). How Women Vote. Bloomberg. https://www.bloomberg.com/quicktake/gender-gap

Aronson, P. (2017). The Dynamics and Causes of Gender and Feminist Consciousness and Feminist Identities. In H. J. McCammon, V. Taylor, J. Reger and R. L. Einwohner (eds.), The Oxford Handbook of U.S. Women's Social Movement Activism (pp. 335-353). New York: Oxford University Press.

Aronson, P. and Fleming, M. (Under Review). Gender Revolution: How Politics and \#MeToo are Reshaping Everyday Life (Book Manuscript).

Aronson, P., Oldham, L. and Lucas, E. (Under Review). '49th Governor of Michigan. Proud Mom:' Gender SelfPresentations in the 2018 Election.

Axios. (2018). Women Campaigning for Office: Then vs. Now. https://www.hbo.com/video/axios/seasons/ season-1/episodes/episode-2/videos/women-campaigning-for-office-then-vs-now

Bauer, N. M. (2015). Emotional, Sensitive, and Unfit for Office? Gender Stereotype Activation and Support Female Candidates. Political Psychology, 36(6), 691-708. https://doi.org/10.1111/pops.12186

Carroll, S. J. (2009). Reflections on Gender and Hillary Clinton's Presidential Campaign: The Good, the Bad, and the Misogynic. Politics \& Gender, 5(1), 1-20. https://doi.org/10.1017/S1743923X09000014

Cascio, E. and Shenhav, N. (2020). A Century of the American Woman Voter: Sex Gaps in Political Participation, Preferences, and Partisanship Since Women's Enfranchisement. The National Bureau of Economic Research, (1). https://doi.org/10.3386/w26709

Conroy, M. (2018). At Least 123 Women Will Be In The Next Congress. Just 19 Are Republicans. FiveThirtyEight. https:// fivethirtyeight.com/features/at-least-123-women-are-headed-to-congress-just-19-are-republicans/

Democrats.org. (2020). https:// democrats.org/who-we-are/

Dittmar, K. (2015). Navigating Gendered Terrain: Stereotypes and Strategy in Political Campaigns. Philadelphia, PA: Temple University Press.

Dwyer, C. E., Stevens, D., Sullivan, J. L. and Allen, B. (2009). Racism, Sexism, and Candidate Evaluations in the 2008 U.S. Presidential Election. Analyses of Social Issues and Public Policy, 9(1), 223-240. https://doi.org/10.1111/j.1530-2415.2009.01187.x

Ellifson, L. (2020). Are the Media Erasing Elizabeth Warren's Presence in the Presidential Race? MSN Nens, February 20. https://www.msn.com/en-us/news/elections-2020/are-the-media-erasing-elizabeth-warren-spresence-in-the-presidential-race $/$ ar-BB107RCG?ocid $=$ msn360

Evans, H. K. and Clark, J. H. (2016). 'You Tweet Like a Girl!' How Female Candidates Campaign on Twitter. American Politics Research, 44(2), 326-352. https://doi.org/10.1177/1532673X15597747

Ferree, M. M. and Hess, B. B. (1994). Controversy \& Coalition: The New Feminist Movement Across Three Decades of Change, Second Edition. New York: Twayne Publishers.

Fountaine, S. (2017). What's not to Like?: A Qualitative Study of Young Women Politicians' Self-Framing on Twitter. Journal of Public Relations Research, 29(5), 219-237. https:/ / doi.org/10.1080/1062726X.2017.1388239

Fridkin, K. L. and Kenney, P. J. (2015). The Changing Face of Representation: The Gender of U.S. Senators and Constituent Communications. Ann Arbor: University of Michigan Press. https://doi.org/10.3998/mpub.6200859 
GOP.com. (2020). https://www.gop.com/platform/

Harris, K. (2019). Sen. Kamala Harris on Being 'Momala. Elle. https://www.elle.com/culture/careerpolitics/a27422434/kamala-harris-stepmom-mothers-day/

Herrnson, P. S., Celeste Lay, J. and Stokes, A. K. (2003). Women Running “as Women”: Candidate Gender, Campaign Issues, and Voter-Targeting Strategies. Journal of Politics, 65(1), 244-255. https://doi.org/10.1111/1468-2508.t01-1-00013

Jungherr, A. (2016). Twitter Use in Election Campaigns: A Systematic Literature Review. Journal of Information Technology \& Politics, 13(1), 72-91. https://doi.org/10.1080/19331681.2015.1132401

Kitzinger, C. (2007). Is 'Woman' Always Relevantly Gendered? Gender and Language, 1(1), 39-49. https://doi.org/10.1558/genl.2007.1.1.39

Klein, E. (April 16, 2019). Pete Buttigieg, Barack Obama, and the psychology of liberalism. Vox. https://www.vox.com/policy-and-politics/2019/4/16/18310769/pete-buttigieg-barack-obama-2020presidential-announcement-hope-primary-democrats

Lawrence, R. G., McGregor, S. C., Cardona, A. and Mourão, R. R. (2016). Personalization and Gender: 2014 Gubernatorial Candidates on Social Media. In Communication and Midterm Elections (pp. 191-206). New York, NY: Palgrave MacMillan.roper. https://doi.org/10.1057/9781137488015_11

McDonnell, A. (2020). Clinton Stated, Trump Exclaimed! Gendered Language on Twitter During the 2016 Presidential Debates. Journal of Language and Politics, 19(1), 71-88. https://doi.org/10.1075/ilp.19085.mcd

McGregor, S. C. (2018). Personalization, Social Media, and Voting: Effects of Candidate Self-Personalization on Vote Intention. New Media \& Society, 20(3), 1139-1160. https://doi.org/10.1177/1461444816686103

McGregor, S. C., Lawrence, R. G. and Cardona, A. (2017). Personalization, Gender, and Social Media: Gubernatorial Candidates' Social Media Strategies. Information, Communication \& Society, 20(2), 264-283. https://doi.org/10.1080/1369118X.2016.1167228

Meeks, L. (2017). Getting Personal: Effects of Twitter Personalization on Candidate Evaluations. Politics \& Gender, 13(1), 1-25. https://doi.org/10.1017/S1743923X16000696

Miles, M. B. and Michael Huberman, A. (1994). Qualitative Data Analysis: An Expanded Sourcebook (Second Edition). Thousand Oaks: Sage Publications.

Roper Center for Public Opinion Research, Cornell University. (July 23, 2017). Madame President: Changing Attitudes about a Woman President. https://ropercenter.cornell.edu/changing-attitudes-about-a-womanpresident/

Schegloff, E. A. (2007). A Tutorial on Membership Categorisation. Journal of Pragmatics, 39(3), 462-482. https:// doi.org/10.1016/j.pragma.2006.07.007

Schneider, M. C. (2013). Gender-Based Strategies on Candidate Websites. Journal of Political Marketing, 13(4), 264-90. https://doi.org/10.1080/15377857.2014.958373

Streb, M. J., Burrell, B., Frederick, B. and Genovese, M. A. (2008). Social Desirability Effects and Support for a Female American President. The Public Opinion Quarterly, 72(1), 76-89. https://doi.org/10.1093/poq/nfm035

Trimble, L., Wagner, A., Sampert, S., Raphael, D. and Gerrits, B. (2013). Is It Personal? Gendered Mediation in Newspaper Coverage of Canadian National Party Leadership Contests, 1975-2012. The International Journal of Press/Politics, 18(4), 462-481. https://doi.org/10.1177/1940161213495455

Ungerleider, N. (June 10, 2013). Hillary Clinton Joins Twitter, Has Best Bio of All Time. FastCompany. https://www.fastcompany.com/3012728/hillary-clinton-joins-twitter-has-best-bio-of-all-time

Wagner, A. (March 15, 2019). Media sexism? Depends on who you are. Policy Options Politiques. https://policyoptions.irpp.org/magazines/march-2019/media-sexism-depends-on-who-you-are/

Wagner, K.M., Gainous, J. and Holman, M. R. (2017). I Am Woman, Hear Me Tweet! Gender Differences in Twitter Use among Congressional Candidates. Journal of Women, Politics, and Policy, 38(4), 430-455. https://doi.org/10.1080/1554477X.2016.1268871

West, C. and Zimmerman, D. H. (1987). Doing Gender. Gender and Society, 1(2, Jun), 125-151. https://doi.org/10.1177/0891243287001002002 